Artigo Original

\title{
Respostas bioquímicas e físicas ao treinamento realizado dentro e fora da água em atletas de futsal
}

\author{
Mabel Micheline Olkoski ${ }^{1}$ \\ Kenji Fuke ${ }^{1}$ \\ Silvana Corrêa Matheus ${ }^{2}$ \\ Félix Alexandre Antunes Soares ${ }^{4}$ \\ Rafael Portella ${ }^{1}$ \\ Edovando José Flores da Rosa ${ }^{1}$ \\ Rômulo Barcelos ${ }^{1}$ \\ Martim Bottaro ${ }^{3}$ \\ ${ }^{1}$ Universidade Federal de Santa Maria, RS, Brasil \\ ${ }^{2}$ Departamento de Métodos e Técnicas Desportivas, Centro de Educação Física \\ e Desportos, Universidade Federal de Santa Maria, RS,Brasil \\ ${ }^{3}$ Faculdade de Educação Física, Universidade de Brasília, DF, Brasil \\ ${ }^{4}$ Departamento de Química, Centro de Ciências Naturais e Exatas, Universidade \\ Federal de Santa Maria, RS, Brasil
}

\begin{abstract}
Resumo: O objetivo deste estudo foi analisar os efeitos do treinamento físico em quadra e do treinamento físico em piscina (hidroginástica) sobre os índices bioquímicos relativos ao dano muscular e a aptidão física de atletas de futsal. Doze jogadores de futsal foram divididos em dois grupos: 1) grupo de treinamento em quadra $(G T Q, n=6)$ e 2$)$ grupo de treinamento em piscina (GTP, $n=6$ ). Foram verificados os índices de capacidades aeróbicas e aneróbicas pelos testes de RAST e Yo-yo intermitent, o dano muscular pela creatina quinase (CK) e lactato desidrogenase (LDH) e os níveis de stress oxidativo pelos níveis de ácido tiobarbitúrico (TBARS) e atividade da catalase (CAT) antes e após 10 sessões de trainamento $(p<0,05)$. Os resultados mostraram que ambos os grupos melhoraram a condição aeróbica após as 10 sessões de treinamento. Mas o GTP apresentou maior atividade da CAT em repouso e menores níveis de CK ao ser comparado com o GTQ na $10^{\text {a }}$ sessão de treino. Concluiu-se que o treino com hidroginástica parece ser uma alternativa interessante para a melhoria das capacidades físicas e para a proteção muscular durante a preparação física inicial de atletas de futsal.
\end{abstract}

Palavras-chave: Dano Muscular. Condicionamento físico. Futsal.

\section{Physical and biochemical responses to training performed in and out of the water in indoor soccer players}

\begin{abstract}
The aim of this study was analyzed the effects of physical training on land and in water (water exercise) on the biochemical levels related to the damage and physical capacity of soccer players. Twelve soccer players were divided into two groups: 1) group training on land (GTL, $n=6$ ) and 2) group training in water (GTW, $n=6)$. Levels of aerobic and anaerobic capacities by RAST and Yo-yo intermittent tests, damage by creatine kinase (CK) and lactate dehydrogenase (LDH), oxidative stress levels by thiobarbituric acid reactive substances (TBARS) and catalase activity (CAT) were evaluated before and after 10 sessions of physical training $(p<0,05)$. The results showed that both groups increased their aerobic capacity after ten training sessions. The GTW presented higher CAT at rest and lower levels of CK to be compared with the GTL at the $10^{\text {th }}$ training session. The conclusion is that training in water seems to be an interesting alternative to improve the physical capacities and to protect muscle during pre season training of indoor soccer players.
\end{abstract}

Keywords: Damage. Physical conditioning. Indoor soccer.

\section{Introdução}

O futsal é um dos esportes mais praticados no mundo (RIBEIRO; COSTA, 2006), mas os trabalhos científicos sobre essa modalidade esportiva são recentes e os que analisam os efeitos do treinamento físico, escassos (CYRINO et al. 2002). Os poucos trabalhos mostram melhoras significativas após 8 a 12 semanas de treino aeróbico, com a preparação física realizada no ambiente terrestre (IAIA et al. 2009) e aquático (TARTARUGA et al. 2009; VENDRÚSCULO, 2005).

Além da melhora do condicionamento físico, outro intuito durante um processo de preparação física eficiente é o cuidado contra a ocorrência de lesões e dano muscular (CLARKSON; HUBAL, 2002). Dados apontam elevações das enzimas plasmáticas como a creatina kinase $(\mathrm{CK})$ e a lactato desidrogenase (LDH), quando o músculo é lesionado (ARMSTRONG, 1986). Além disso, 
respostas moleculares de um quadro de stress oxidativo (ácido tiobarbitúrico e atividade da catalase) mostram indícios do efeito do treinamento sobre o organismo do atleta, que podem prever com maior antecedência os desgastes musculares (NETO et al. 2006), dando margens para a modulação das cargas de treino.

Estudos que avaliaram a resposta desses parâmetros foram realizados na sua grande maioria no meio terrestre, e verificaram apenas resultados após uma sessão de treino, demonstrando aumentos das substâncias reativas ao ácido tiobarbitúrico (TBARS) (LEE et al. 2002; FRANÇA et al. 2006), da LDH (FRANÇA et al. 2006) e da CK (FRANCA et al. 2006; PANTOJA et al. 2009). Os trabalhos realizados no meio aquático são escassos. Nenhum trabalho com hidroginástica foi encontrado na literatura pesquisada, sendo encontrados estudos com a natação (NETO et al. 2006; DA SILVA et al. 2009), o nado sincronizado (PAZIKAS et al. 2005), o cicloergômetro (PANTOJA et al. 2006; 2009) e a corrida em piscina funda (VENDRÚSCULO, 2005; TARTARUGA et al. 2009). Esses estudos têm encontrado melhora do consumo máximo de oxigênio $\left(\mathrm{VO}_{2} \mathrm{máx}\right)$ igual ao treino em terra (VENDRÚSCULO, 2005), mas com menores níveis de CK (PANTOJA et al. 2009; VENDRÚSCULO, 2005) ou sem alteração dessa enzima após uma sessão de treino (PAZIKAS et al. 2005). Além disso, efeitos agudos foram obtidos por Da Silva et al. (2009) que verificaram aumentos da atividade da catalase (CAT) após uma sessão de natação sem aumento das TBARS nem de CK.

Assim, sugere-se que 0 treino no meio aquático seja uma alternativa que poderia ser benéfica na prevenção do dano muscular ao mesmo tempo em que melhoraria as capacidades físicas de atletas. Estudos com hidroginástica tornam-se relevantes uma vez que ela favorece a realização de movimentos variados durante uma sessão, que podem ir desde os que englobam diferentes grupos musculares até a realização de movimentos específicos. Nesse sentido, o objetivo deste estudo foi analisar os efeitos do treinamento físico em piscina (aulas de hidroginástica) e do treinamento físico em quadra sobre os índices bioquímicos relativos ao dano muscular e a aptidão física de atletas de futsal.

\section{Métodos}

\section{Sujeitos}

Foram avaliados 12 jogadores de futsal que treinavam há no mínimo 1 ano. Os indivíduos foram divididos por conveniência em dois grupos a fim de que cada um fosse composto por todas as posições de jogo do futsal. O grupo submetido ao treino físico em quadra (GTQ) foi composto por 6 sujeitos. Os outros 6 fizeram parte do grupo submetido ao treino físico em piscina (aulas de hidroginástica) (GTP). Tanto o GTQ quanto o GTP fizeram o mesmo treino técnico/tático em dois dias distintos do treino físico durante a semana. Cabe ressaltar que os sujeitos não realizavam outro tipo de exercício durante a fase estudada.

\section{Composição Corporal (CC)}

A mensuração da $C C$ foi realizada com 0 objetivo de caracterizar o grupo investigado. Foram realizadas medidas de estatura (estadiômetro de madeira, precisão de $0,5 \mathrm{~cm}$ ), massa corporal (balança Welmy, precisão $0,100 \mathrm{~kg}$ ) e dobras cutâneas (compasso Cescorf $^{T M}$, precisão $0,1 \mathrm{~mm}$ ).

A densidade corporal (PETROSKI, 1995) foi utilizada para obtenção do percentual de gordura corporal (\%GC) através da fórmula de Siri (1961). As características de ambos os grupos são apresentadas na tabela 1.

Tabela 1. Caracterização dos sujeitos quanto à média e desvio padrão da idade, da estatura, da massa corporal e do percentual de gordura corporal (\%GC).

\begin{tabular}{|c|c|c|}
\hline $\begin{array}{ll}\text { Medidas } & \text { Grupos } \\
\end{array}$ & GTQ $(n=6)$ & GTP $(n=6)$ \\
\hline Idade (anos) & $23,14 \pm 3,39$ & $21,67 \pm 1,63$ \\
\hline Estatura $(\mathrm{cm})$ & $177,83 \pm 10,33$ & $172,67 \pm 6,84$ \\
\hline Massa corporal $(\mathrm{kg})$ & $79,69 \pm 7,90$ & $70,83 \pm 3,58$ \\
\hline$\% G C$ & $12,83 \pm 3,52$ & $9,82 \pm 3,27$ \\
\hline
\end{tabular}

$\mathrm{GTQ}=$ grupo submetido ao treino físico em quadra; GT GTP=grupo submetido ao treino físico em piscina (aulas de hidroginástica). 


\section{Determinação do condicionamento físico}

A condição anaeróbica foi obtida a partir da realização do teste RAST (DRAPER; WHYTER, 1997).

Já para a verificação da condição aeróbica, foi realizado o teste progressivo máximo em quadra Yo-Yo Intermitent (BANGSBO et al., 2008). Antes da realização do mesmo, cada probando permaneceu sentado por 10 minutos, monitorado por um frequencímetro (Polar modelo Accurex Plus). Ao final desse tempo, foram registrados valores de frequência cardíaca de repouso $(\mathrm{FCr})$ e pressão arterial (PA) (Esfigmomanômetro e estetoscópio) para verificação dos parâmetros de repouso necessários para a realização de um teste máximo. Logo após, realizou-se o teste e ao finalizá-lo, foi verificada a frequência cardíaca (FC) para todos os sujeitos, considerada como a FC máxima (FCmáx).

Determinação da Ceratina quinase (CK), lactato desidrogenase (LDH), ácido tiobarbitúrico (TBARS) e atividade da catalase (CAT)

A coleta de sangue foi à vácuo em tubos contendo EDTA (obtenção de plasma e eritrócitos) sem anticoagulante (obtenção de soro) e após realizou-se a centrifugação dos mesmos a 4000rpm durante 10 minutos. A CK (ROSALKI, 1967) e a LDH (WHITAKER, 1969) foram avaliadas a partir do soro dos voluntários. As dosagens foram feitas por kits comerciais adquiridos do labtest análises espectrofotométricas. Já as TBARS foram avaliadas conforme descrito por Ohkawa et al. (1979) com algumas modificações. O plasma foi

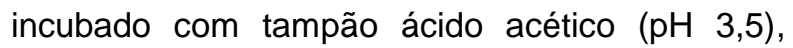
dodecil sulfato de sódio $10 \%$ e ácido tiobarbitúrico $0,6 \%$ a $90^{\circ} \mathrm{C}$ durante 1 hora. Após, os tubos foram centrifugados por 10 minutos a 4000rpm. O sobrenadante foi utilizado para a leitura espectofotométrica em 532nm, utilizando-se malondialdeído como padrão. A atividade da CAT foi determinada conforme metodologia de Aebi (1984). Eritrócitos foram hemolisados com água destilada e deionizada. O hemolisado foi utilizado na determinação da degradação de peróxido de hidrogênio em tampão fosfato $(\mathrm{pH} 7,0) \mathrm{em}$ espectrofotômetro a $240 \mathrm{~nm}$ durante 2 minutos. A atividade enzimática foi determinada pelo coeficiente de extinção molar do peróxido de hidrogênio $\left(43,6 \mathrm{M}^{-1} \mathrm{~cm}^{-1}\right)$.
Determinação da intensidade das sessões de treino

O controle da intensidade de esforço foi realizado através do controle da FC. A intensidade foi estipulada individualmente, conforme sugerido por McArdle et al. (2001), onde é necessária a obtenção de valores de $\mathrm{FCr}$ e FCmáx. Para o GTP, a FCr foi o menor valor obtido durante 5 minutos onde o sujeito permaneceu em repouso, na posição ortostática, imerso até a altura do processo xifóide (ALBERTON et al. 2007), monitorado por um frequencímetro (Polar). Os sujeitos pertencentes ao GTQ, também monitorizados por um frequencímetro (Polar), permaneceram em pé na quadra durante 5 minutos. O menor valor de FC obtido durante os 5 minutos foi o utilizado como FCr para esse grupo.

A FCmáx de cada sujeito foi a encontrada no final do teste progressivo máximo Yo-YO Intermitent (BANGSBO et al. 2008) realizado por todos os sujeitos e descrito anteriormente. Assim, calculou-se incialmente a $\mathrm{FC}$ de reserva $\left(\mathrm{FC}_{\mathrm{res}}\right)$, onde $\mathrm{FC}_{\text {res }}=\mathrm{FCmáx}-\mathrm{FCr}$. Após, foi realizado 0 cálculo da $\mathrm{FC}$ de treino $\left(\mathrm{FC}_{\text {treino }}\right)$ (limites inferior $\mathrm{e}$ superior) através da equação: $\mathrm{FC}_{\text {treino }}=\mathrm{FC}_{\text {res }} \mathrm{x} \%$ de trabalho+FCr (McARDLE et al. 2001).

Os sujeitos realizaram todos os treinos monitorados pelo frequencímetro. Durante os treinos com o GTP, a FC foi verificada por um auxiliar a cada 1 minuto e 10 segundos, momento no qual era realizada a troca de exercício, sendo que o mesmo grupo muscular era mantido por 2 minutos e 20 segundos (MORAES et al. 2002). Já durante os treinos com o GTQ, a FC foi verificada por um auxiliar a cada 2 minutos (McARDLE et al. 2001), sendo esse o momento da mudança de exercício. Os sujeitos de ambos os grupos eram constantemente instruídos a realizar as sessões dentro da faixa de treinamento previamente estipulada. Caso os sujeitos não estivessem atingindo a intensidade adequada, eram estimulados a aumentar a velocidade do exercício.

A intensidade aumentou progressivamente durante as 10 sessões de treino. Nos quatro primeiros treinos, a intensidade foi de 60 a $70 \%$ da FCmáx, nos outros três treinos, a intensidade foi de 60 a $85 \%$ da FCmáx, sendo que os dois últimos tiveram características intermitentes, com variações de 50 a $90 \%$ da FCmáx. 


\section{Estrutura das sessões de treino}

A fase inicial e final dos treinos foi comum aos dois grupos e cada uma delas teve duração de cinco minutos. A fase inicial foi composta por alongamentos musculares e aquecimento articular de membros inferiores e superiores. Já na fase final foram realizados apenas exercícios de alongamento dos principais grupos musculares utilizados.

O GTP realizou o treino em uma piscina coberta com profundidades que variaram de $1 \mathrm{~m}$ a $1,2 \mathrm{~m}$, permitindo que todos os sujeitos realizassem as aulas imersas até a altura do processo xifóide (ALBERTON et al. 2007). A temperatura da água (termômetro de mercúrio, $\left.0,1^{\circ} \mathrm{C}\right)$ foi termoneutra (McARDLE et al. 1976). Durante a fase principal (30 minutos) das quatro primeiras aulas de hidroginástica, foram realizados exercícios com movimentos dos membros inferiores e superiores. Durante as três aulas seguintes, foram realizados predominantemente exercícios específicos de corrida, deslocamentos laterais, Deep Water Running (DWR) e adução e abdução de quadril, sendo que na aula 8 e 9 (transição para a fase específica), os exercícios de corrida estática e com deslocamento foram predominantes.

Com relação ao GTQ, os treinos foram realizados em uma quadra de piso de madeira e coberta. Todas as aulas foram compostas por corridas e deslocamentos laterais em várias direções e distâncias.

\section{Procedimentos}

Inicialmente foi realizada uma reunião com a equipe juntamente com seu responsável técnico para apresentação do objetivo e breve explicação sobre o presente trabalho. Após, os sujeitos foram convidados a fazer parte como voluntários. Todos que se disponibilizaram, assinaram o termo de consentimento livre e esclarecido aprovado pelo Comitê de Ética em Pesquisa da UFSM (0177.0.243.000-09). Em um primeiro momento foi realizada a avaliação da CC e o teste para verificação da condição anaeróbica (RAST). Após 24 horas (hs), os indivíduos foram submetidos ao teste progressivo máximo em quadra (Yo-Yo Intermitent) para determinação da condição aeróbica. Outras $24 \mathrm{hs}$ foram estabelecidas como intervalo para a próxima avaliação que se consistiu na primeira sessão de treino e obtenção das variáveis bioquímicas. Para tanto, os sujeitos permaneceram inicialmente sentados durante 10 minutos para a coleta de $5 \mathrm{ml}$ de sangue venoso na situação de repouso (rep1a $1^{\mathrm{a}}$ ). Foram coletados outros $5 \mathrm{ml}$ na situação após (apos 1 $1^{\mathrm{a}}$ ), 24hs (24hs1 $\left.1^{a}\right)$ e $48 \mathrm{hs}\left(48 \mathrm{hs} 1^{\mathrm{a}}\right)$ após a $1^{\underline{a}}$ sessão de treino. Esse mesmo procedimento ocorreu na $10^{\mathrm{a}}$ sessão de treino (rep10 48hs $10^{\mathrm{a}}$ ). Após 48hs, foram realizados novamente o RAST e o Yo-Yo Intermitent, com intervalo de $24 \mathrm{hs}$ entre os mesmos.

A fase de treinamento estudada compreendeu o período de preparação (BORIN et al. 2007) composta por 5 semanas, sendo que foram realizadas 2 sessões de treino por semana, totalizando 10 sessões. Durante este período os sujeitos investigados não realizaram nenhum outro tipo de exercício físico, exceto as sessões de treino técnico/tático que ocorreram em outros dois dias na semana.

Todos os sujeitos realizaram no mínimo $80 \%$ do total de treinos físicos, técnicos e táticos durante o desenvolvimento do presente estudo.

\section{Análise estatística}

Após analisar a normalidade dos dados, foi utilizado o Teste $t$ pareado para comparação entre os dados de condicionamento físico obtidos na $1^{\text {a }}$ e na $10^{\underline{a}}$ sessão de treino para cada grupo. Para a comparação entre os grupos, foi utilizado o Teste $t$ para amostras independentes. Já a comparação de cada variável bioquímica em cada momento de avaliação na $1^{\underline{a}}$ e na $10^{\underline{a}}$ sessão entre GTP e GTQ, utilizou-se o Teste de Mann-Wihtney-U. O índice de significância adotado foi de $5 \%$ e o pacote estatístico utilizado foi o BioEstat, versão 5.0 .

\section{Resultados}

Os resultados referentes à capacidade aeróbico e anaeróbico dos atletas no início e no final das 10 sessões são apresentados na tabela 2.

Pode-se observar que houve melhoras da capacidade aeróbica (distância percorrida no teste de Yo-yo Intermitent) em ambos os grupos (GTQ $p=0,0024$ e GTP $p=0,0010)$ após as 10 sessões de treino.

Outra análise de interesse no presente trabalho foi em relação aos parâmetros bioquímicos. Para o grupo que realizou o treinamento em quadra, os resultados referentes às variáveis bioquímicas não apresentaram diferenças entre as avaliações realizadas na $1^{\underline{a}} \mathrm{e}$ 
na $10^{\circ}$ sessão de treino. Já o grupo que realizou o treinamento em piscina, verificou-se aumentos $(\mathrm{p}=0,0050)$ na CAT na situação rep10 $0^{\mathrm{a}}$ (28 $\mu \mathrm{molH}_{2} \mathrm{O}_{2} / \mathrm{min} / \mu \mathrm{L}$ ) quando comparada a situação $\operatorname{rep}^{\text {a }}$ (23 $\left.\mu \mathrm{molH}_{2} \mathrm{O}_{2} / \mathrm{min} / \mu \mathrm{L}\right)$.

Ao comparar as variáveis bioquímicas obtidas na $10^{\text {a }}$ sessão entre o GTQ e o GTP pode-se constatar que a CK apresentou diferenças em alguns momentos. Os níveis foram mais baixos para o GTP nas situações rep10 ${ }^{\mathrm{a}} \quad(\mathrm{p}=0,0273)$, após10 a $(p=0,0032)$ e 24hs10 após $p=0,0022)$. Esses resultados podem ser visualizados na figura 1.

Tabela 2. Resultados médios e desvio padrão do RAST (Potência Média, Potência Máxima e Índice de Fadiga Muscular - IFM) e do Yo-yo Intermitent (Distância) antes da $1^{\text {a }}$ e depois da $10^{a}$ sessão de treino para o GTQ e o GTP.

\begin{tabular}{|c|c|c|c|c|}
\hline \multirow[b]{2}{*}{ Variáveis } & \multicolumn{2}{|c|}{ GTQ $(n=6)$} & \multicolumn{2}{|c|}{$\operatorname{GTP}(n=6)$} \\
\hline & $1^{\underline{a}}$ & $10^{\mathrm{a}}$ & $1^{\text {a }}$ & $10^{\mathrm{a}}$ \\
\hline Potência Média (W/kg) & $7,48 \pm 1,09$ & $7,53 \pm 1,15$ & $7,37 \pm 1,84$ & $7,78 \pm 1,15$ \\
\hline Potência Máxima (W/kg) & $9,74 \pm 2,12$ & $9,45 \pm 1,86$ & $9,12 \pm 2,73$ & $10,17 \pm 2,82$ \\
\hline IFM (W/seg) & $9,67 \pm 4,72$ & $8,33 \pm 2,31$ & $7,20 \pm 4,09$ & $9,40 \pm 3,91$ \\
\hline Distância (m) & $1104,29 \pm 312$ & $1294,29 \pm 301^{*}$ & $970,00 \pm 297$ & $1214,00 \pm 311^{*}$ \\
\hline
\end{tabular}

${ }^{*}$ Diferenças estatisticamente significativa entre as 10 sessões de treino para cada grupo.

$\mathrm{GTQ}=$ grupo submetido ao treino físico em quadra;

GTP=grupo submetido ao treino físico em piscina (aulas de hidroginástica).

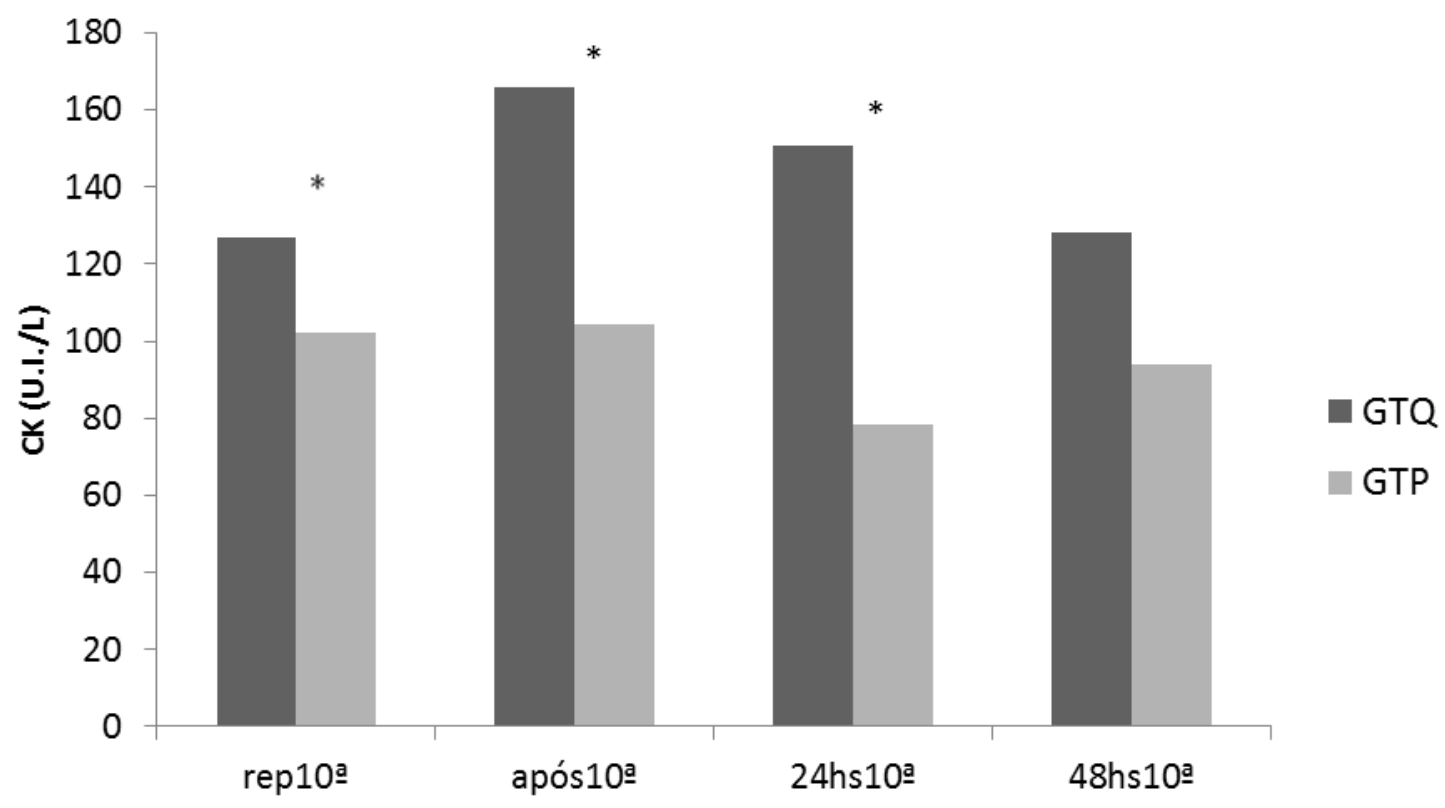

Avaliações referentes à 10 ạ sessão de treino

${ }^{*}$ Diferença $(p<0.05)$ entre o GTQ e o GTP em cada momento de avaliação.

rep $10^{a}=$ =repouso antes da $10^{\underline{a}}$ sessão; após $10^{\mathrm{a}}=$ =após a $10^{\underline{a}}$ sessão; $24 \mathrm{hs} 10^{\underline{a}}=24 \mathrm{hs}$ após a $10^{\mathrm{a}}$ sessão; $48 \mathrm{hs} 10^{\underline{a}=}=48 \mathrm{hs}$ após a $10^{\mathrm{a}}$ sessão.

Figura 1. Comparação entre o grupo submetido ao treino em quadra (GTQ) e o grupo submetido ao treino na piscina (GTP) com relação aos níveis da creatina quinase (CK) durante as avaliações realizadas na $10^{\text {a }}$ sessão de treino.

\section{Discussão}

A melhora do condicionamento aeróbico no futebol parece ser fundamental. Os trabalhos têm mostrado correlação entre a melhora do $\mathrm{VO}_{2}$ máx e da distância percorrida com o número de sprints realizados durante o jogo (HOFF; HELGERUD, 2004). No presente estudo, a prática da hidroginástica como alternativa para a melhora da condição aeróbica no período de preparação, parece ser tão eficiente quanto o treino realizado em quadra normalmente utilizado pela equipe avaliada (Tabela 2). Outros trabalhos também encontraram melhoras cardiorrespiratórias semelhantes com corredores iniciantes que realizaram 0 treino em piscina funda 
(VENDRÚSCULO, 2005; TARTARUGA et al. 2009), mostrando que o meio aquático parece ser uma alternativa eficiente para a melhora dessa condição física tanto para atletas como para iniciantes.

Essa melhora no condiconamento físico aeróbico também mostra que o objetivo para a fase de treinamento em questão foi atingido, já que é nesse momento em que essa condição deve ser enfatizada nesta modalidade (BORIN et al. 2007).

laia et al. (2009) revisaram a literatura e verificaram que tanto treinos aeróbicos de $60-80 \%$ da FCmáx quanto os de velocidade com duração de 8 a 12 semanas são eficientes na melhora do desempenho dos atletas. No presente trabalho, realizou-se um aumento progressivo da carga de trabalho (de $60-70 \%$ até $50-90 \%$ da FCmáx) durante a fase estudada e verificou-se que em 5 semanas ocorrem melhoras na condição aeróbica.

Um treinamento eficiente também é aquele que tende a reduzir ao máximo a exposição do atleta à lesão. A análise dos níveis de CK na corrente sanguínea é uma das formas indiretas mais utilizadas para a análise do dano muscular (JAMURTAS et al. 2005). Os resultados aqui encontrados (gráfico 1) sugerem que a realização do exercício no meio líquido submete o organismo a um menor stress muscular após 10 sessões de treino quando comparado ao treino realizado em quadra, corroborando com os achados de Vendrúsculo (2005) que avaliaram corredores não treinados.

Esses resultados distintos entre os meios onde o exercício é realizado podem ser explicados pelo tipo de contrações musculares predominantes em cada situação. O movimento realizado na água tem predominância das ações concêntricas (PANTOJA et al. 2006) devido à flutuabilidade (HARRISON et al. 1992), onde a maior densidade da água quando comparada com a do ar (FRANGOLIAS; RHODES, 1995) dificulta o posicionamento do corpo fazendo com que o exercício concêntrico seja predominante, o que não ocorre no meio terrestre. $O$ aumento dos níveis de CK após a realização de exercícios que envolvam contrações predominantemente excêntricas é bem confirmado pela literatura (CHEN; HSIEH, 2001; DOLEZAL et al. 2000; EVANS et al. 2002; MILLIAS et al. 2005). Proske e Morgan, (2001) explicam que no exercício excêntrico, o músculo sofre contratação ao mesmo tempo em que é forçosamente alongado, o que não ocorre nos exercícios concêntricos, onde o músculo é encurtado.

Com relação às variáveis do estado redox, somente o GTP apresentou aumento da CAT na situação rep $10^{\underline{a}}$ quando comparada rep $1^{\text {a }}$. Como a CAT é um composto enzimático antioxidade (POWERS; JACKSON, 2008), significa dizer que sua presença retarda e inibe significativamente a oxidação de um substrato que estaria supostamente agredindo a atividade celular (HALLIWELL; GUTTERIDGE, 2006), podendo justificar os baixos níveis de CK no GTP. No único trabalho encontrado na literatura pesquisada realizado no meio líquido (DA SILVA et al. 2009) os autores analisaram duas sessões de natação, com um intervalo de apenas $12 \mathrm{hs}$ e encontraram resultados semelhantes aos apresentados pelo GTP. Os resultados mostraram aumentos da CAT após a $1^{1}$ sessão de natação e não encontraram aumento de compostos oxidantes (TBARS) nem de CK. No entanto, após a $2^{\text {a }}$ sessão, foram verificados aumentos de todos os parâmetros, o que pode ser justificado pelo curto espaço de intervalo entre as sessões de natação. Os resultados do presente estudo sugerem que a preparação física através da hidroginástica faz com que a CAT aumente na situação de repouso, fazendo com que o tecido muscular seja menos lesado nessa situação e que poderia justificar a menor concentração de $\mathrm{CK}$ ao comparar os dois grupos estudados.

Ao comparar a capacidade antioxidante de jogadores de futebol e sujeitos sedentários, Brites et al. (1999) verificaram que os atletas possuem maior capacidade antioxidante e também aumento de alguns marcadores de stress oxidativo. Embora a literatura seja carente com relação a estudos conduzidos em jogadores de futebol e análise bioquímica, pois nenhum com futsal foi encontrado na literatura estudada, alguns trabalhos relatam aumento na atividade das enzimas antioxidantes em eritrócitos após treinamento aeróbico (SELAMOGLU et al. 2000) em corredores (ROBERTSON et al. 1991) e ciclistas profissionais (MENA et al. 1991), o que não aconteceu com todos os atletas de futsal, do presente estudo.

Sen (2001) revisa a literatura e afirma que a suplementação de antioxidantes para atletas muitas vezes é necessária. Mas os tipos e as 
doses são difíceis de serem definidas, onde os atletas deveriam buscar uma estimativa individual, - que muitas vezes é inviável. Diferentes estratégias têm sido utilizadas em estudos com voluntários e animais ao longo dos últimos anos na tentativa de aumentar a capacidade antioxidante do indivíduo, tais como a suplementação com antioxidantes, restrições dietéticas e fármacos (CRUZAT et al. 2007). Nenhuma destas alternativas isoladas demonstrou aumento da capacidade de defesa do organismo (JI, 2002). De acordo com Finque e Holbrook (2000), a estratégia mais eficiente em aumentar a quantidade endógena de antioxidantes pode ser a maior indução do próprio stress oxidativo que, gradativamente, estimularia os mecanismos antioxidantes celulares e aumentaria a resistência a lesões induzidas pelo exercício (EBBELING; CLARKSON, 1989; $\underline{\text { HEATH }}$ et al. 1981). Essa teoria parece ter efeito também no presente estudo. Especula-se que o GTP ao realizar o exercício na água, melhorou de forma significativa a atividade da CAT após as 10 sessões, o que não aconteceu com o GTQ.

De forma geral, pode-se concluir que o treino em piscina (aulas de hidroginástica) melhora o condicionamento aeróbico, a CAT em repouso e apresenta níveis mais baixos de CK. Dessa forma, esse treino parece ser o mais adequado caso o objetivo seja a melhora da condição física com ênfase na proteção contra lesões durante a preparação física de atletas de futsal com características semelhantes ao grupo estudado.

\section{Referências}

AEBI, H. Catalase in vitro. Methods in Enzymology, Pasadena. n. 105, p. 121-127, 1984.

ALBERTON, C.L.; OLKOSKI, M.M.; PINTO, S.S.; BECKER, M.E.; KRUEL, L.F.M. Cardiorrespiratory responses of postmenopausal women to different water exercises. International Journal of Aquatic Research and Education, Bowling Green, v. 1, n.4, p. 363-372, 2007.

ARMSTRONG, R.B. Muscle damage and endurance events. Sports Medicine,

Gewerbestrasse, v. 3, n. 5, p. 370-381, 1986. doi: http://dx.doi.org/10.2165/00007256-198603050$\underline{00006}$.

BANGSBO, J.; IAIA, M.; KRUSTRUP, P. The YoYo Intermitent Recovery Test. A useful tool for evaluation of physical performance in intermittent sports. Sports Medicine, Gewerbestrasse v. 38, n. 1, p. 37-51, 2008.

BORIN, J.P.; GOMES, A.C.; LEITE, G.S. Sporting preparation: aspects of load training control in collective games. Revista da Educação Física. Maringá, v. 18, n. 1, p. 97-105, 2007.

BRITES, F.D.; EVELSON, P.A.; CHRISTIANSEN, M.G.; NICOL, M.F.; BASÍLICO, M.J.; WIKINSKI, R.W.; LLESUY, S.F. Soccer players under regular training show oxidative stress but an improved plasma antioxidant status. Clinical Science, Londres, v. 96, n. 4, p. 381-385, 1999.

CHEN, T.C.; HSIEH, S.S. Effects of a 7-day eccentric training period on muscle damage and inflammation. Medicine and Science in Sports and Exercise, Indianápolis, v. 33, n. 4, p. 17321738, 2001.

CLARKSON, P.M.; HUBAL, M.J. ExerciseInduced Muscle Damage in Humans. American Journal of Physical Medicine and

Rehabilitation, Indianápolis, v. 81 , n. 11, p. S52S69, 2002.

CRUZAT, V.F.; ROGERO, M.M.; BORGES, M.C.; TIRAPEGUI, J. Aspectos atuais sobre estresse oxidativo, exercícios físicos e suplementação.

Revista Brasileira de Medicina do Esporte, São Paulo, v. 13, n. 5, p. 336-342, 2007.

CYRINO, E.S.; ALTIMARI, L.R.; OKANO, A.H.; COELHO, C.F. Effects of futsal training on the body composition and motor performance of young athletes. Revista Brasileira de Ciência e Movimento, Brasília, v. 10, n. 1, p. 41-46, 2002.

DA SILVA, L.A.; ROCHA, L.G.C.; SCHEFFER, D.; SOARES, F.S.; PINHO, C.A.; POLIZELLI, A.B.; SILVEIRA, P.C.L.; PINHO, R.A. Resposta de duas sessões de natação sobre parâmetros de estresse oxidativo em nadadores. Revista Brasileira de Cineantropometria eDesempenho Humano, Florianópolis, v. 11, n. 2, p. 160-165, 2009.

DOLEZAL, B.A.; POTTEIGER, J. A.; JACOBSEN, D.J.; BENECICT, S.H. Muscle damage and resting metabolic rate after acute resistance exercise with an eccentric overload. Medicine and Science in Sports and Exercise, Indianápolis, v. 32, n. 7, p. 1202-1207, 2000.

DRAPER, N.; WHYTE, G. Here's a new running based test of anaerobic performance for which you need only a stopwatch and a calculator. Peak Performance, Londres, v. 97, n. 1, p. 3-5, 1997.

EBBELING, C.B.; CLARKSON, P.M. Exerciseinduced muscle damage and adaptation. Sports 
Medicine, Gewerbestrasse, v. 7, n. 4, p. 207-234, 1989.

EVANS, R.K.; KNIGHT, K.L.; DRAPER, D.O.; PARCELL, A.C. Effects of warm-up before eccentric exercise on indirect markers of muscle damage. Medicine and Science in Sports and Exercise, Indianápolis, v. 34, n. 12, p. 1892-1899, 2002.

FINKEL, T.; HOLBROOK, N.J. Oxidants, oxidative stress and the biology of ageing. Nature, Oxford, v. 408, p. 239-247, 2000. doi:

http://dx.doi.org/10.1038/35041687.

FRANGOLIAS, D.D.; RHODES, E.C. Maximal and ventilatory threshold responde to treadmill and water immersion running. Medicine and Science in Sports and Exercise, Indianápolis, v. 27, n. 7, p. 1007-1013, 1995.

FRANÇA, S.C.A.; NETO, T.L.B.; AGRESTA, M.C.; LOTUFO, R.F.M.; KATER, C.E. Resposta divergente da testosterona e do cortisol séricos em atletas masculinos após uma corrida de maratona. Arquivo Brasileiro de Endocrinologia e Metabalismo, São Paulo, v. 50, n. 6, p. 10821087, 2006. http://dx.doi.org/10.1590/S0004$\underline{27302006000600015}$.

HALLIWELL, B.; GUTTERIDGE, J.M.C. Free Radicals in Biology and Medicine. Oxford: Clarendon Press, 2006

HARRISON, R. A.; HILLMAN, M.; BULSTRODE, $S$. Loading of the lower limb when walking partially immersed: implications for clinical practice.

Physiotherapy, Philidelphia, v. 78, n. 3, p. 164166, 1992. doi: http://dx.doi.org/10.1016/S00319406(10)61377-6.

HEATH, G.W.; HAGBERG, J.M.; EHSANI, A.A.; HOLLOSZY, J.O. A physiological comparison of young and older endurance athletes. Journal of Applied Physiology, Bethesda, n. 51, p. 634-40, 1981.

HOFF, J.; HELGERUD, J. Endurance and strength training for soccer players physiological considerations. Sports Medicine,

Gewerbestrasse, v. 34, n. 3, p. 165-180, 2004.

IAIA, F.M.; RAMPININI, E.; BANGSBO, J. Highintensity training in football. International Journal of Sports Physiology and Performance, La Crosse, v. 4, n. 3, p. 291-306, 2009.

JAMURTAS, A.Z.; THEOCHARIS, V.; TOFAS, T.; TSIOKANOS, A.; YFANTI, C.; PASCHALIS, V.; KOUTEDAKIS, Y.; NOSAKA, K. Comparison between leg and arm eccentric exercises of the same relative intensity on indices of muscle damage. European Journal of Applied
Physiology, Berlin, v. 95, n. 2-3, p. 179-185, 2005. doi: http://dx.doi.org/10.1007/s00421-0051345-0.

JI, L.L. Exercise-induced modulation of antioxidant defense.Annals of the New York Academy of Sciences, New York, v. 959, n. 1, p. 82-92, 2002. doi: http://dx.doi.org/10.1111/i.17496632.2002.tb02085.x.

LEE, J.; GOLDFARB, A.H.; RESCINO, M.H.; HEDGE, S.; PATRICK, S.; APPERSON, K. Eccentric exercise effect on blood oxidative-stress markers and delayed onset of muscle soreness. Medicine and Science in Sports and Exercise, Indianápolis, v. 34, n. 3, p. 443-448, 2002.

McARDLE, W.D.; MAGEL, J.R.; LESMES, G.R.; PECHAR, C.S. Metabolic and cardiovascular adjustment to work in air and water at 18, 25 and $33^{\circ} \mathrm{C}$. Journal of Applied Physiology, Bethesda, v. 40 , n. 1, p. 85-90, 1976.

McARDLE, W.D.; KATCH, F.I.; KATCH, V.L. Fisiologia do exercício - energia, nutrição e desempenho humano. Rio de Janeiro: Guanabara Koogan, 2001.

MENA, P.; MAYNAR, M.; GUTIERREZ, J.M.; MAYNAR, J.; TIMON, J.; CAMPILLO, J.E. Erythrocyte free radical scavenger enzymes in bicycle professional racers: adaptation to training. International Journal of Sports Medicine, Stuttgart, v. 12, n. 6, p. 563-566, 1991. doi: http://dx.doi.org/10.1055/s-2007-1024734.

MILLIAS, G.A.; NOMIKOS, T.; FRAGOPOULOU, E.; ATHANASOPOULOS, S.; ANTONOPOULOU, $\mathrm{S}$. Effects of eccentric exercise-induced muscle injury on blood levels of platelet activating factor (PAF) and other inflammatory markers. European Journal of Applied Physiology, Berlin, v. 95, n. 5-6, p. 504-513, 2005. doi: http://dx.doi.org/10.1007/s00421-005-0031-6.

MORAES, E.Z.C.; KRUEL, L.F.M.; SAMPEDRO, R.M.F.; LOPES, L.F.D. Metodologia de medida de esforço para exercícios de hidroginástica em diferentes profundidades de água. Kinesis, Santa Maria, v. 64, n. 1, p. 43-64, 2002.

NETO, J.M.F.A.; TOYAMA, M.H.; CARNEIRO, E.M.; BOSCHERO, A.C.; DA SILVA, L.P.; MACEDO, D.V. Circulating leukocyte heat shock protein 70(HSP70) and oxidative stress markers in rats after a bout of exhaustive exercise. Stress, Edinburgh, v. 9, n. 2, p. 107-115, 2006. doi: http://dx.doi.org/10.1080/10253890600772211.

OHKAWA, N.; OHISHI, H.; YAGI, K. Assay for lipid peroxides in animal tissues by thiobarbituric acid reaction. Analytical Biochemistry, Bethesda, v. 95, n. 2, p. 351-358, 1979. 
PANTOJA, P.D.; VENDRUSCULO, A.P.; FAYH, A.P.; ALBERTON, C.L.; KRUEL, L.F.M.

Respostas hemodinâmicas, cardiorrespiratórias e ocorrência de lesão muscular no meio aquático e terrestre em mulher não ativa: estudo de caso.

Motriz, Rio Claro, v. 12, n. 3, p. 277-282, 2006.

PANTOJA, P.D.; ALBERTON, C.L.; PILLA, C.; VENDRUSCULO, A.P.; KRUEL, L.F.M. Effect of resistive exercise on muscle damage in water and on land.Journal of Strength \& Conditioning

Research, Connecticut, v. 23, n. 3, p. 1051-1054, 2009. doi:

http://dx.doi.org/10.1519/JSC.0b013e3181a00c45.

PAZIKAS, M.G.A.; CURI, A.; AOKI, M.S.

Comportamento de variáveis fisiológicas em atletas de nado sincronizado durante uma sessão de treinamento na fase de preparação para as Olimpíadas de Atenas 2004. Revista Brasileira de Medicina do Esporte. São Paulo, v. 11, n. 6, p. 357-362, 2005.

PETROSKI, E.L. Desenvolvimento e validação de equações generalizadas para a estimativa da densidade corporal em adultos: 1991-1995. Tese de Doutorado - Universidade Federal de Santa Maria, Santa Maria.1995.

POWERS, S.K.; JACKSON, M.J. Exerciseinduced oxidative stress: cellular mechanisms and impact on muscle force production. Physiological Reviews, Bethesda, v. 88, n. 4, p. 1243-1276, 2008.

PROSKE, U.; MORGAN, D.L. Muscle damage from eccentric exercise: mechanism, mechanical signs, adaptation and clinical applications.

Journal of Physiology, Oxford, v. 537, n. 2, p. 333-345, 2001. doi:

http://dx.doi.org/10.1111/j.1469-

7793.2001.00333.x.

RIBEIRO, R.N.; COSTA, L.O.P. Análise epidemiológica de lesões no futebol de salão durante o XV Campeonato Brasileiro de Seleções Sub 20. Revista Brasileira de Medicina do Esporte, São Paulo, v. 12, n. 1, p. 1-5, 2006.

ROBERTSON, J.D.; MAUGHAN, R.J.; DUTHIE, G.G.; MORRICE, P.C. Increased blood antioxidant systems of runners in response to training load.

Clinical Science, Londres, v. 80, n. 6, p. 611-618, 1991.

ROSALKI, S.B. An improved procedure for serum creatine phosphokinase determination. Journal of Laboratory and Clinical Medicine, Mosby, v. 69, n. 4, p. 696-705, 1967.

SELAMOGLU, S.; TURGAY, F.; KAYATEKIN, B.M.; GONENC, S.; YSLENGEN, C. Aerobic and anaerobic training effects on the antioxidant enzymes of the blood. Acta Physiologica

Hungarica, Budapest, v. 87, n. 3, p. 267-273, 2000.

SEN, C.K. Antioxidants in exercise nutrition.

Sports Medicine, Gewerbestrasse,v. 31, n. 13, p. 891-908, 2001.

SIRI, W.E. Body composition from fluid spaces and density: analysis of methods. In: BROZEK, J.; HENSCHEL, A. (Eds.), Thechniques for measuring body composition. Washington, DC: National Academy of Sciences, 1961.

TARTARUGA, L.A.P.; TARTARUGA, M.P.; COERTJENS, M.; BLACK, G.L.; OLIVEIRA, A.R.; KRUEL, L.F.M. Physiologic and Kinematical Effects of Water Run Training on Running Performance. International Journal of Aquatic Research and Education, Bowling Green, v. 3, n. 2, p. 135-150, 2009.

\section{VENDRÚSCULO, A.P. Análise de lesão muscular e comportamento do $\mathrm{VO}_{2}$ máx entre um programa de treinamento de corrida em piscina funda e corrida em terra: 2001-2005. Dissertação de Mestrado - Universidade Federal do Rio Grande do Sul, Porto Alegre.}

WHITAKER, J.F. A general colorimetric procedure for the estimation of enzymes which are linked to the NADH-NAD system. Clinica Chimica Acta, Philidelphia, v. 24, n. 1, p. 23-27, 1969. doi: http://dx.doi.org/10.1016/0009-8981(69)90137-5.

\section{Endereço:}

Mabel Micheline Olkoski

Av. Bento Gonçalves, 2174 Centro

Ametista do Sul RS Brasil

98465-000

Telefone: (55) 3752-1184

e-mail: mabelolkoski@hotmail.com

Recebido em: 08 de março de 2012.

Aceito em: 27 de abril de 2013.

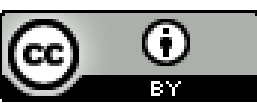

Motriz. Revista de Educação Física. UNESP, Rio Claro, SP, Brasil - elSSN: 1980-6574 - está licenciada sob Creative Commons - Atribuição 3.0 